\title{
MICROBIAL KERATITIS- MICROBIAL PATTERN IN A TERTIARY CARE CENTRE OF A METROPOLITAN CITY
}

\author{
Vrunda MorePatil1, Sapna Malik2, Minu Ramakrishnan³, Jyothirlatha Bangera4
}

${ }_{1}^{1}$ Assistant Professor, Department of Ophthalmology, K. J. Somaiya Medical College, Mumbai, Maharashtra, India.

${ }^{2}$ Associate Professor, Department of Microbiology, K. J. Somaiya Medical College, Mumbai, Maharashtra, India.

3 Professor, Department of Ophthalmology, K. J. Somaiya Medical College, Mumbai, Maharashtra, India.

${ }^{4}$ Professor, Department of Microbiology, K. J. Somaiya Medical College, Mumbai, Maharashtra, India.

\begin{tabular}{l}
\hline ABSTRACT \\
BACKGROUND \\
Microbial keratitis is a potentially vision threatening state requiring prompt diagnosis \& treatment, and is a leading cause of \\
preventable blindness. We wanted to study the spectrum and sensitivity of microbiological isolates from patients of microbial \\
keratitis at a tertiary care centre of a metropolitan city.
\end{tabular}

\section{METHODS}

Descriptive data collection and analysis was carried out in a tertiary care centre over a period of 3 years. The cases were the grouped based upon their positivity in microscopy and culture results and correlated with clinical data.

\section{RESULTS}

258 clinical cases were studied, of which 173 cases were bacterial keratitis, and 85 were fungal keratitis. Of 173 (67.05\%) bacterial cases, 68 (39.30\%) cases showed positive findings on gram stain, and 25 (36.76\%) of these cases were confirmed by culture. Of 85 (32.94\%) fungal cases, 37 (43.53\%) cases were positive on KOH mount \& 21 (56.76\%) of these cases were confirmed by culture.

\section{CONCLUSIONS}

Incidence of bacterial keratitis is higher than fungal keratitis. Emphasis should be on using microbiological diagnosis as an important tool to aid the ophthalmologist in appropriate management of these cases.

HOW TO CITE THIS ARTICLE: MorePatil V, Malik S, Ramakrishnan M, et al. Microbial keratitis- microbial pattern in a tertiary care centre of a metropolitan city. J. Evolution Med. Dent. Sci. 2019;8(14):1145-1149, DOI: 10.14260/jemds/2019/254

\section{BACKGROUND}

Microbial Keratitis or infectious corneal ulcer is due to proliferation of bacteria, fungi, viruses, parasites and the associated inflammation and tissue destruction within the cornea. A potentially vision threatening state requiring prompt diagnosis \& treatment and a leading cause of preventable blindness. ${ }^{1}$ The causative organisms include bacteria, amoebae (Acanthamoeba) and fungi (yeasts and moulds). Keratitis is characterized by acute onset of pain, conjunctival injection and corneal ulceration with a stromal inflammatory infiltrate. Depending on size and location of ulcer vision may be impaired. There are large regional differences in the relative prevalence of each of these causative organisms which are determined by climate \& socioeconomic factors. ${ }^{2}$ Importantly, risk factors for infection change periodically due to certain factors like increase in number of contact lens users and corrective refractive surgery. Therefore, monitoring of changing patterns of disease and causative agents with their sensitivity profile proves essential.

'Financial or Other Competing Interest': None.

Submission 18-02-2019, Peer Review 23-03-2019,

Acceptance 29-03-2019, Published 08-04-2019.

Corresponding Author:

Dr. Sapna Malik,

C 1201,

Jal Vayu Vihar,

ADS Marg, Near Hiranandani Gardens,

Powai, Mumbai-400076,

Maharashtra,

India.

E-mail: sapnawadhwan@hotmail.com

DOI: $10.14260 /$ jemds/2019/254

\section{(c) (i) $(9)$}

Clinical diagnosis is based on clinical history and slit lamp examination of a bacterial corneal ulcer would be most likely with the following signs and symptoms: - conjunctival injection with sharp epithelial demarcation and underlying stromal inflammation, corneal thinning, stromal oedema, endothelial inflammatory plaque, Descemet's folds, mucopurulent discharge, anterior chamber reaction and hypopyon. Diagnosing a fungal ulcer - corneal ulcers unresponsive to broad-spectrum antibiotics, the presence of satellite lesions, scanty secretions in a large ulcer are some signs that should raise flags to the attending professional about the possibility of a mycotic agent. Blurred vision, redness, tearing, photophobia, pain, foreign body sensation and secretions related to trauma, ocular surface disease and or topical steroid use.

With filamentary fungi the corneal lesions have a white/grey infiltrate with feathery borders. Ulcers caused by yeast are plaque like and slightly more defined, similar to bacterial keratitis. ${ }^{2,3}$

Infections of the cornea can lead to corneal opacity and blindness without timely identification and judicious management. Keratitis is an urgent problem requiring prompt diagnosis laboratory evaluation and appropriate therapeutic intervention. It is a serious ocular problem, which if denied of appropriate and timely management can lead to vision threatening complications such as corneal scarring, perforation, endophthalmitis and ultimately blindness. A particular feature of bacterial keratitis is its rapid progression, corneal destruction may be complete in 24-48 hours in case of a highly virulent bacteria. Corneal ulceration, stromal abscess formation, surrounding corneal oedema and anterior segment inflammation are characteristic of this disease. Keratitis remains one of the most threatening and 
potential complications of contact lens use. Keeping all the above in mind timely diagnosis and appropriate intervention are the key towards the avoidance and minimizing any vision threatening sequelae. In addition to frequent and regular follow up and laboratory evidence, modification of antimicrobial medication is needed in cases of no clinical improvement, these prove as important elements for a successful therapeutic outcome. Guidelines for management of microbial keratitis need to be formulated giving due consideration to local patterns of infection and antimicrobial sensitivities. Though treatment guidelines are often based on laboratory sensitivity, relevance of in vitro drug sensitivity results are often uncertain due to differential sensitivity observed in vitro and in vivo settings. ${ }^{3}$

In this study, a descriptive Study review of medical records of all microbiologically diagnosed cases of Bacterial \& Fungal keratitis seen over a period of 3 years at a tertiary care centre were studied with the following objectives-

a) To carry out an analysis of the data with respect to samples sent for Microbiological investigations including $\mathrm{KOH}$ preparation, staining, culture and sensitivity from Microbial keratitis cases.

b) To analyse the various microbial isolates and sensitivity pattern of bacterial isolates.

\section{METHODS}

Descriptive data collection and analysis was carried out in a tertiary care centre over a period of 3 years. The cases were the grouped based upon their positivity in microscopy and culture results and correlated with clinical data.

\section{Clinical Procedure}

The visual acuity was measured in standard manner. Corneal sensation and lacrimal sac patency were confirmed. All patients were examined under slit lamp bio-microscope. The size of ulcer was measured after staining with wet sterile fluorescein paper strip using slit on the slit lamp. Ulcer margin, floor, thinning, satellite lesions, type of the infiltrations, pigmentation on the ulcer surface any impacted foreign body, presence of hypopyon, associated ocular signs and use of topical medication if any were noted. Grading of site, size and severity was done.

The procedure was explained to the patient. The patient is positioned comfortably at the slit-lamp. The patient was instructed to keep both eyes open during the procedures to avoid blinking which would add to discomfort. Local anaesthetic eye drops are instilled to the affected eye to minimise ocular discomfort and facilitate the corneal scraping procedure. A sterile stainless-steel blade no.15 was used to scrape the base of the ulcer with care. This is to ensure that the infective material is reached as the microorganisms may lie deep or at the edge of the ulcer. The collected material is plated on the growth media and/or carefully spread on a glass slide. The area around the material is marked for Gram staining or $\mathrm{KOH}$ preparation. Once procedure done, the patient is given instruction for appropriate eye care i.e. hand washing, eyelid hygiene and instillation of an antibiotic eye drops. All specimens are correctly labelled and sent to the microbiology laboratory. A sterile swab of the corneal lesion was taken and rotated 360 degrees onto the ulcer so as to obtain an adequate sample.4,5,6

\section{Microbiological Follow Up}

Microscopic studies included gram stain, $\mathrm{KOH}$ preparation to determine aetiology whether bacterial or fungal and these samples were cultured on routine media for bacterial and fungal isolates. The bacterial isolates further were subjected to antimicrobial sensitivity testing for routinely used antibiotics. Cultures were inoculated on Blood agar, Chocolate agar, MacConkey's agar for bacterial culture and on Sabouraud's dextrose agar with and without antibiotics for fungal culture. All the bacterial and fungal isolates obtained on culture were identified by microscopy i.e. $\mathrm{KOH}$ preparation, Grams staining, LPCB (Lactophenol cotton blue) mounts and biochemical properties using standard laboratory criteria. Microbiological cultures were considered positive if only they were consistent with the gram stain and/or $\mathrm{KOH}$ preparation.

\section{RESULTS}

Clinical Diagnosis: The clinical signs most commonly used to differentiate ulcers were infiltrate border appearance, surrounding stromal haze, and the presence (Or absence) of hypopyon. The same clinical signs were listed as most helpful in the graders' clinical decision the clinical signs noted most often were central location of the infiltrate, the absence of a plaque, well-delineated borders and moderate surrounding stromal haze. The predictive abilities of clinical signs were analysed with respect to the known aetiology based on laboratory testing and not the clinical determination. The presence of irregular/ feathery borders was strongly associated with fungal keratitis. The treatment of fungal and bacterial keratitis is distinctly different, and individual organisms may be best treated by tailored therapy, appropriate microbiologic evaluation were strongly considered during the initial clinical encounter. As stated above these included: serrated infiltrate margins, raised slough, dry texture, satellite lesions, hypopyon, anterior chamber fibrin, and color. Serrated infiltrate margins and raised slough (Surface profile) were independently associated with fungal keratitis, and the anterior chamber fibrin was independently associated with bacterial keratitis. ${ }^{7,8,9,10,11}$ As per the above criteria, 258 cases of Microbial Keratitis were further diagnosed as Bacterial (173) and Fungal (85) Keratitis presumptively and were confirmed by microbiological workup. All the cases were subjected to microbiological follow up. 


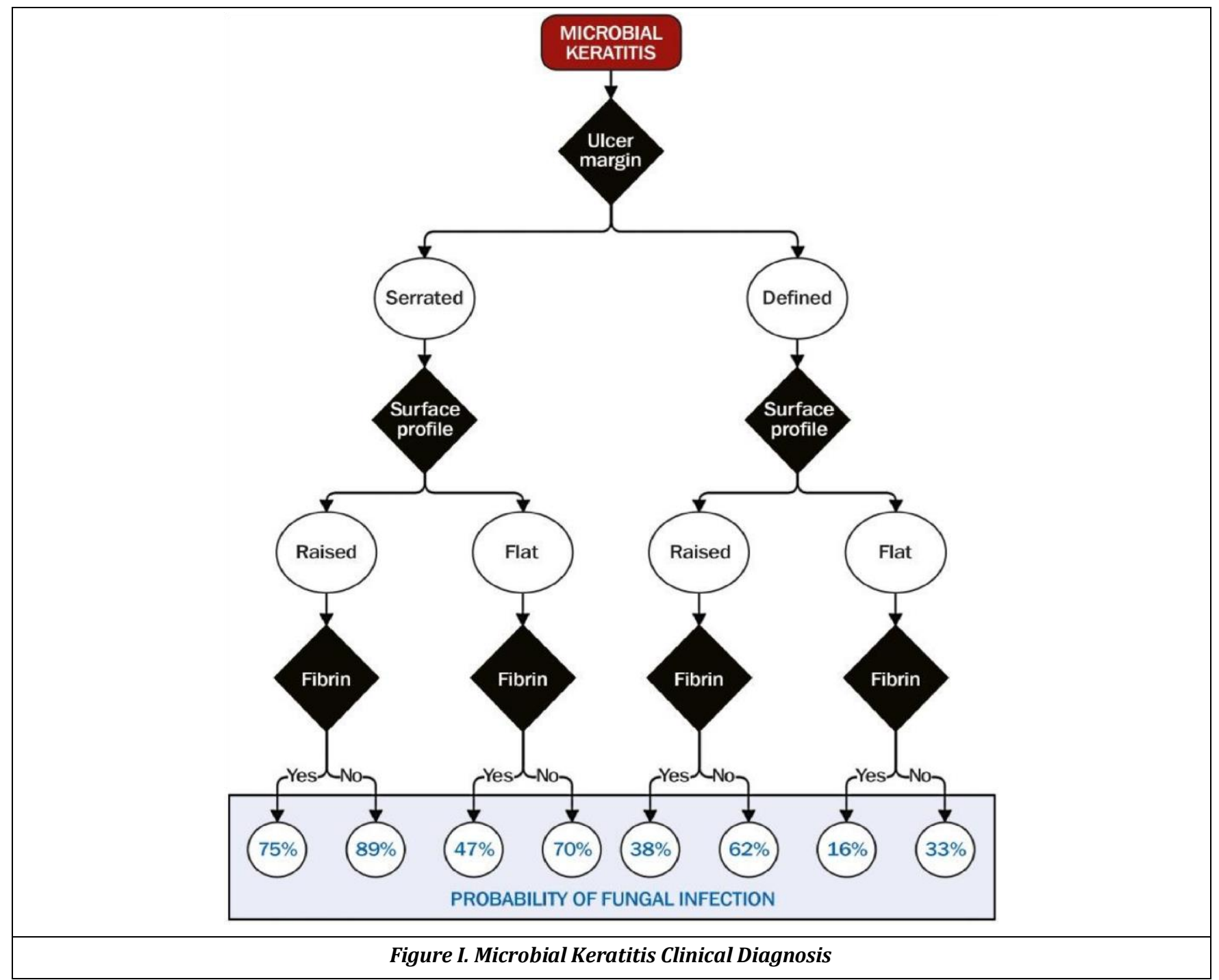

258 presumptive cases of Microbial keratitis were sent to the microbiology laboratory for investigations, of these 258 presumptive cases $105(40.69 \%)$ cases were confirmed microbiologically either by microscopy and/ or culture as bacterial or fungal keratitis.

\section{Microbiological Diagnosis}

Of 173 bacterial keratitis cases 68 (39.3\%) cases showed positivity on gram stain and of these 68 cases $25(36.76 \%)$ cases were culture positive, $47(27.17 \%)$ cases gram stain revealed plenty of pus cells, but no organisms were seen. 68 cases showed positive findings on gram staining - 48 (70.56\%) cases gram staining revealed gram negative bacilli with plenty of pus cells from these $20(80 \%)$ cases grew Pseudomonas aeruginosa. The other $20(29.41 \%)$ cases 19 revealed gram-positive cocci and 1 case showed gram positive bacilli on gram staining. From the 20 cases of grampositive cocci and gram-positive bacilli only 5 (20\%) cases grew gram positive cocci and gram-positive bacilli on culture, $2(8 \%)$ cases each grew Staphylococcus aureus and Streptococcus species each and $1(4 \%)$ case grew Diphtheroids. All the isolates were sensitive to all drugs tested in the laboratory as per CLSI guidelines. The following drugs were tested for Pseudomonas aeruginosa - Amikacin, Gentamicin, Ciprofloxacin, Tobramycin, Ceftazidime, Piperacillin-Tazobactam, Aztreonam, Polymyxin B, Colistin and Cotrimoxazole. The drugs tested for Staphylococcus aureus and Streptococcus species were Penicillin, Cotrimoxazole, Ofloxacin, Ciprofloxacin, Levofloxacin, Erythromycin, Clindamycin, Linezolid, Vancomycin, Cefazolin and Ceftriaxone. All isolates showed good sensitivity to majority of the drugs tested there by helping the clinician in prompt treatment of all the patients. Of 85 fungal keratitis cases 37 (43.53\%) were positive on $\mathrm{KOH}$ preparation and 25 (29.41\%) cases showed plenty of pus cells on gram staining but no fungal elements were reported on $\mathrm{KOH}$ preparation. From 37 cases positive by $\mathrm{KOH}$ preparation and gram staining, 21(56.76\%) were confirmed by culture and were identified by slide culture \& lactophenol cotton blue mount. From $37 \mathrm{KOH}$ preparation positive cases $24(64.86 \%)$ cases showed aseptate hyphae in $\mathrm{KOH}$ preparation from these 24 cases 11(52.38\%) cases grew Aspergillus species and $4(19.04 \%)$ grew Fusarium species. In 13(35.14\%) cases budding yeast cells were seen, from these 13 only 06(28.57\%) cases grew Candida species.

\begin{tabular}{|c|c|c|c|}
\hline $\begin{array}{c}\text { Sr. } \\
\text { No. }\end{array}$ & $\begin{array}{c}\text { Total Number of } \\
\text { Samples(68) }\end{array}$ & $\begin{array}{c}\text { Gram Staining } \\
\text { Positivity }\end{array}$ & $\begin{array}{c}\text { Gram Staining } \\
\text { Positivity (\%) }\end{array}$ \\
\hline 1 & Gram Positive & 48 & 70.56 \\
\hline 2 & Gram Negative & 20 & 29.41 \\
\hline \multicolumn{3}{|c|}{ Table I. Distribution of Samples Based on Gram Stain } \\
Positivity (Bacterial Keratitis)
\end{tabular}




\begin{tabular}{|c|c|c|c|}
\hline Sr. No. & Bacterial Growth & Number of Samples & $\mathbf{( \% )}$ \\
\hline 1 & Pseudomonas aeruginosa & 20 & 80 \\
\hline 2 & Staphylococcus aureus & 2 & 8 \\
\hline 3 & Streptococcal species & 2 & 8 \\
\hline 4 & Diphtheroids & 1 & 4 \\
\hline \multicolumn{2}{|r|}{ Table II. Bacterial Growth in Culture Positive Samples } \\
\hline
\end{tabular}

Table II. Bacterial Growth in Culture Positive Samples

\begin{tabular}{|c|c|c|c|c|}
\hline $\begin{array}{c}\text { Total } \\
\text { Number of } \\
\text { Samples }\end{array}$ & $\begin{array}{c}\text { KOH \& } \\
\text { Gram } \\
\text { Staining } \\
\text { Positivity }\end{array}$ & $\begin{array}{c}\text { KOH \& } \\
\text { Gram } \\
\text { Staining } \\
\text { Positivity } \\
\text { (\%) }\end{array}$ & $\begin{array}{c}\text { Culture } \\
\text { Positivity }\end{array}$ & $\begin{array}{c}\text { Culture } \\
\text { Positivity } \\
\text { (\%) }\end{array}$ \\
\hline 85 & 37 & 43.53 & 21 & 56.76 \\
\hline
\end{tabular}

Table III. Positivity of Samples Based on KOH Preparation and Gram Stain (Fungal Keratitis)

\begin{tabular}{|c|c|c|c|}
\hline Sr. No. & Fungal Growth & Number of Samples & $\mathbf{( \% )}$ \\
\hline 1 & Aspergillus Species & 11 & 52.38 \\
\hline 2 & Fusarium Species & 04 & 19.04 \\
\hline 3 & Candida Species & 06 & 28.57 \\
\hline
\end{tabular}

Table IV. Fungal Growth in Culture Positive Samples

\section{DISCUSSION}

In the present study descriptive data analysis was done of the patients attending the Ophthalmology outpatient department at a tertiary care centre. The patients included in the study were of presumptive Microbial Keratitis, 173 cases of bacterial cases $68(39.30 \%)$ positively correlated with gram stain findings, from these 68 cases 25 (36.76\%) grew organisms on culture which included 20 (80\%) isolates Pseudomonas aeruginosa, $2(8 \%)$ isolates each of Staphylococcus aureus and Streptococcus species and $1(4 \%)$ isolate of Diphtheroids species. From 173 cases 47 (27.17\%) cases showed plenty of pus cells on gram's staining but no organisms were seen, and cultures were negative for growth. This may be attributed to excessive use of topical antimicrobials with or without topical steroids or being treated previously by another consultant before attending the outpatient department at our centre.

Amongst the 85 presumptive fungal cases $\mathrm{KOH}$ preparations and gram stain findings indicative of fungal elements was seen in $37(43.53 \%)$ cases and of these 37 cases $21(56.76 \%)$ grew fungi in culture. In 24 cases $(64.86 \%)$ plenty of pus cells and aseptate hyphae were reported and in 13 (35.14\%) plenty of pus cells with budding yeast cells were reported. Culture positive cases the isolates identified were Aspergillus species in 11(52.38\%) cases, Fusarium species in 04(19.04\%) cases amongst moulds and Candida species in $06(28.57 \%)$ cases. In $25(29.41 \%)$ of 85 cases of fungal keratitis plenty of pus cells were seen on gram stain but no fungal elements were recorded on $\mathrm{KOH}$ preparation this may be seen if antifungal agents have been prescribed before patient reports to the outpatient department or improper collection or scanty material received on a corneal scrape.

In this study bacterial keratitis rates are $39.3 \%$, bacterial keratitis rates have been reported as $32.3 \%$ in Madurai 11 $29.3 \%$ in Thiruchirapalli in South India ${ }^{12} 40 \%$ in Egypt, 13 $38 \%$ in Mexico, ${ }^{14} 35.6 \%$ in South Florida 15 and $25 \%$ in Southern Ghana ${ }^{16}$ whereas in a marked contrast, a study in Nepal has documented evidence of $63.2 \%$ of cases of corneal ulcers having a bacterial aetiology. 17
The present study is comparable with a study done by Bharthi M.J. et al where $32.77 \%$ cases are bacterial but the rate of fungal infection in present study is $43.53 \%$ is higher than the study done in South India where rate of fungal infection is $33.26 \%{ }^{18}$ Fudnawala et al reported the bacterial keratitis rate of infection higher i.e. $49.38 \%$ and rate of fungal infection is lower than the present study at $33.33 \%$. The most common bacterial isolate in their study was Staphylococcus aureus followed by Pseudomonas aeruginosa, whereas Pseudomonas aeruginosa is the most common isolate in present study followed by Staphylococcus aureus. ${ }^{2}$ In a study by Bourcier et al the rate of bacterial keratitis at $68 \%$ is considerably higher than present study but the commonest organisms isolated by them is Pseudomonas aeruginosa amongst the gram negative organisms which is comparable with present study. ${ }^{19}$ Rate of bacterial keratitis and Pseudomonas aeruginosa being the most commonly isolated organism is comparable with a Mexican study by HernandezCamerena JC et al with 38\% cases of bacterial Keratitis. ${ }^{14}$ In a South Florida study by Alexandrakis $G$ et al, again Pseudomonas aeruginosa was the most common bacterial isolate. $^{20}$ Whereas in an Auckland study Staphylococcus aureus was isolated followed by Pseudomonas aeruginosa and in present study infection with Staphylococcus aureus are much lower. ${ }^{21}$ The bacterial strains showed moderate to high resistance with the following drugs Amoxicillin, Chloramphenicol, Penicillin, Ciprofloxacin And Cefuroxime whereas the isolates in present study were sensitive to all the drugs tested. There are various risks factors for drug resistance in keratitis such as repeated antibiotic usage, ocular surface disease, hospital acquired infections, postsurgical infections, infection from medical personnel and non-responsive severe keratitis which should be considered while treating such patients. ${ }^{3}$

The present study has $43.53 \%$ of confirmed fungal cases with Aspergillus species being the common isolate amongst fungi which is in accordance to study done by A.E. Badawi et al $^{13}$ where $45.5 \%$ samples had pure fungal infection and Aspergillus species was the commonest fungal isolate. Present study can also be compared with Fudnawala et al who have reported Aspergillus species as the common fungal isolate followed by Fusarium species though the fungal infection rate was only $33 \% .^{2}$ In a study from Nepal by Yogesh Acharya et al Aspergillus species, Fusarium species and Candida species are some of the common etiological agents for fungal keratitis. ${ }^{22}$ In another study by Gopinathan $\mathrm{U}$ et al from South India fungal cause of keratitis was $95.4 \%$ which is much higher than present study. ${ }^{23}$

Microbial Keratitis is a significant health problem and the differences seen in the number of cases is due to variety of predisposing factors such as contact lens users, trauma due to vegetative matter, injury, foreign body or insects, steroid use, underlying diseases such as diabetes to name a few.1,3 Regional differences are seen in the isolates cultured from keratitis patients due to difference in climate and natural environment. Information on regional differences are extremely important with regard to empirical treatment as many patients may not have access to a microbiological work up for their condition and hence it would be helpful for formation of guidelines on Microbial Keratitis in high risk population so as to have prompt treatment and prevent further complications. 24 


\section{CONCLUSIONS}

1. Pseudomonas aeruginosa is the most common bacterial isolate followed by Staphylococcus aureus and Streptococcus species from bacterial keratitis patients.

2. Aspergillus species, Candida species and Fusarium species are the common fungal etiological agents from cases of fungal keratitis.

3. In our tertiary care centre, incidence of fungal keratitis is on the increase which can be attributed to more topical steroids and antibiotic use along with predisposing factors such as underlying disease and low socioeconomic status.

4. KOH preparation along with Gram staining is a reliable method for detecting fungal aetiology as compared to fungal culture, as culture takes much longer incubation for most fungal etiological agents.

5. Clinical judgment, awareness of risk factors, and having a good microbiology laboratory work-up helps guide the clinicians to institute appropriate and prompt therapeutic management in order to preserve vision of the patient and achieving desirable results.

6. Bacterial isolates in the study showed good sensitivity to most antimicrobial agents tested, thereby making it easier for the clinician to treat such cases.

\section{REFERENCES}

[1] Jeng BH, McLeod SD. Microbial Keratitis. Br J Ophthalmol 2003;87(7):805-6.

[2] Fudnawala V, Gandhi G, Soni KN, et al. Epidemiology \& etiological characteristics of microbiological diagnosed cases of bacterial \& fungal keratitis in Baroda India. Delhi Journal of Ophthalmology 2006;11(2):75-81.

[3] Cornea DOS Times, Delhi Ophthalmology Society. 2018;23(2):16-28.

[4] Shi W, Li S, Liu M, et al. Antifungal chemotherapy for fungal keratitis guided by in vivo confocal microscopy. Graefes Arch Clin Exp Ophthalmol 2008;246(4):581-6.

[5] Rondeau N, Bourcier T, Chaumeil C, et al. Fungal keratitis at the Centre Hospitalier National d'Ophtalmologie des Quinze-Vingts: retrospective study of 19 cases. J Fr Ophtalmol 2002;25(9):890-6.

[6] Ocular Pathology Atlas. American Academy of Ophthalmology website. https://www.aao.org/resident-course/pathologyatlas. Published 2016. Accessed on January 4, 2017.

[7] Varaprasathan G, Miller K, Lietman T, et al. Trends in the etiology of infectious corneal ulcers at the F. I. Proctor Foundation. Cornea 2004;23(4):360-4.

[8] Norina TJ, Raihan S, Bakiah S, et al. Microbial keratitis: aetiological diagnosis and clinical features of patients admitted to Hospital Universiti Sains Malaysia. Singapore Med J 2008;49(1):67-71.

[9] Ibrahim YW, Boase DL, Cree IA. Epidemiological characteristics, predisposing factors and microbiological profiles of infectious corneal ulcers: the Portsmouth corneal ulcer study. Br J Ophthalmol 2009;93(10):1319-24.
[10] Keay L, Edwards K, Naduvilath T, et al. Microbial keratitis: predisposing factors and morbidity. Ophthalmology 2006;113(1):109-16.

[11] Srinivasan M, Gonzales CA, George $C$, et al. Epidemiology and aetiological diagnosis of corneal ulceration in Madurai, South India. Br J Ophthalmol 1997;81(11):965-71.

[12] Leck AK, Thomas PA, Hagan M, et al. Aetiology of suppurative corneal ulcers in Ghana and South India and epidemiology of fungal keratitis. Br J Ophthalmol 2002;86(11):1211-5.

[13] Badawi AE, Moemen D, El-Tantawy NL. Epidemiological, clinical and laboratory findings of infectious keratitis at Mansoura Ophthalmic Center, Egypt. Int J Ophthalmol 2017;10(1):61-7.

[14] Hernandez-Camarena JC, Graue-Hernandez EO, OrtizCasas M, et al. Trends in microbiological and antibiotic sensitivity patterns in infectious keratitis: 10-year experience in Mexico City. Cornea 2015;34(7):778-85.

[15] Liesegang TJ, Forster RK. Spectrum of microbial keratitis in south Florida. Am J Ophthalmol 1980;90(1):38-47.

[16] Hagan M, Wright E, Newman M, et al. Causes of suppurative keratitis in Ghana. $\mathrm{Br} \mathrm{J}$ Ophthalmol 1995;79(11):1024-8.

[17] Upadhyay MP, Karmacharya PC, Koirala S, et al. Epidemiological characteristics, predisposing factors and etiologic diagnosis of corneal ulceration in Nepal. Am J Ophthalmol 1991;111(1):92-9.

[18] Bharthi MJ, Ramakrishnan R, Vasu S, et al. Epidemiology of bacterial keratitis in a referral centre in South India. Indian Journal of Medical Microbiology 2003;21(4):239-45.

[19] Bourcier T, Thomas F, Borderie V, et al. Bacterial keratitis: predisposing factors clinical and microbiological review of 300 cases. Br J Ophthalmol 2003;87(7):834-8.

[20] Alexandrakis G, Alfonso EC, Miller D. Shifting trends in bacterial keratitis in south Florida and emerging resistance to fluoroquinolones. Ophthalmology 2000;107(8):1497-502.

[21] Marasini S, Swift S, Dean SJ, et al. Spectrum and sensitivity of bacterial keratitis isolates in Auckland. Article ID 3769341, J Ophthalmol 2016;2016: p. 8.

[22] Acharya Y, Acharya B, Karki P. Fungal keratitis: study of increasing trend and common determinants. Nepal J Epidemiol 2017;7(2):685-93.

[23] Gopinathan U, Garg P, Fernandes M, et al. The Epidemiological features and laboratory results of fungal keratitis: a 10-year review at a referral eye center in south India. Cornea 2002;21(6):555-9.

[24] Basak SK, Basak S, Mohanta A, et al. Epidemiological and microbiological diagnosis of suppurative keratitis in Gangetic West Bengal. Indian J Ophthalmol 2005;53(1):17-22. 